\title{
Complex Analyses of Short Inverted Repeats in All Sequenced Chloroplast DNAs
}

\author{
Václav Brázda $\mathbb{D},{ }^{1}$ Jiř́i Lýsek $\mathbb{D},{ }^{2}$ Martin Bartas $\mathbb{D}^{3},{ }^{3}$ and Miroslav Fojta ${ }^{1}$ \\ ${ }^{1}$ The Czech Academy of Sciences, Institute of Biophysics, Královopolská 135, 61265 Brno, Czech Republic \\ ${ }^{2}$ Department of Informatics, Mendel University in Brno, Zemědělská 1, 61300 Brno, Czech Republic \\ ${ }^{3}$ Department of Biology and Ecology/Institute of Environmental Technologies, Faculty of Science, \\ University of Ostrava, Ostrava, Czech Republic \\ Correspondence should be addressed to Václav Brázda; vabdna@gmail.com
}

Received 15 March 2018; Revised 19 June 2018; Accepted 12 July 2018; Published 24 July 2018

Academic Editor: Peter J. Oefner

Copyright (C) 2018 Václav Brázda et al. This is an open access article distributed under the Creative Commons Attribution License, which permits unrestricted use, distribution, and reproduction in any medium, provided the original work is properly cited.

Chloroplasts are key organelles in the management of oxygen in algae and plants and are therefore crucial for all living beings that consume oxygen. Chloroplasts typically contain a circular DNA molecule with nucleus-independent replication and heredity. Using "palindrome analyser" we performed complete analyses of short inverted repeats (S-IRs) in all chloroplast DNAs (cpDNAs) available from the NCBI genome database. Our results provide basic parameters of cpDNAs including comparative information on localization, frequency, and differences in S-IR presence. In a total of 2,565 cpDNA sequences available, the average frequency of $\mathrm{S}$-IRs in cpDNA genomes is $45 \mathrm{~S}$-IRs/per kbp, significantly higher than that found in mitochondrial DNA sequences. The frequency of S-IRs in cpDNAs generally decreased with S-IR length, but not for S-IRs 15, 22, 24, or 27 bp long, which are significantly more abundant than S-IRs with other lengths. These results point to the importance of specific S-IRs in cpDNA genomes. Moreover, comparison by Levenshtein distance of S-IR similarities showed that a limited number of S-IR sequences are shared in the majority of cpDNAs. S-IRs are not located randomly in cpDNAs, but are length-dependently enriched in specific locations, including the repeat region, stem, introns, and tRNA regions. The highest enrichment was found for $12 \mathrm{bp}$ and longer S-IRs in the stem-loop region followed by $12 \mathrm{bp}$ and longer S-IRs located before the repeat region. On the other hand, S-IRs are relatively rare in rRNA sequences and around introns. These data show nonrandom and conserved arrangements of S-IRs in chloroplast genomes.

\section{Introduction}

Inverted repeat sequences (IRs) play an important regulation role in genomic DNA [1]. It has been demonstrated that short IRs (S-IRs) are essential for DNA replication in both prokaryotes and eukaryotes [2]. Depending on their length, sequence, and crowding conditions, S-IRs can form a local DNA structure called cruciform, which is a target of numerous DNAbinding proteins with important regulatory functions [3]. Among these proteins are cruciform resolving proteins like E. coli enzyme RuvA $[4,5]$ and proteins important for human diseases including the 14-3-3 [6] and p53 protein families $[7,8]$. Similarly, high mobility group- (HMG-) like cruciform binding proteins have also been purified from plants [9] and it was demonstrated that IRs in chloroplast DNA (cpDNA) genomes play a role in evolution and various regulatory processes $[10,11]$. Both chloroplasts and mitochondria retain their own genomes and transcription machinery. S-IRs in mitochondrial DNA ( $m t D N A)$ are located nonrandomly with high abundance in the replication origin, D-loop, and stemloop sequences [12]. While mitochondria are present in all eukaryotes, chloroplasts are exclusive for algae and plants. Therefore, it is thought that mitochondria were engulfed before the origin of chloroplasts by a common ancestor. This is also supported by the fact that mtDNA is usually shorter than cpDNA.

Chloroplasts are semiautonomous organelles; their origin dates back to over 1,000 million years ago, when an ancient cyanobacterium was engulfed by a eukaryotic cell (primary endosymbiotic event), which subsequently gave rise to glaucophytes, red algae, green algae, and plants [13] and probably most recently to the filose amoeba Paulinella 
chromatophore [14]. Subsequent secondary, serial secondary, and tertiary endosymbiotic processes have been important during the evolution of modern photosynthetic eukaryotes [15]. In land plants, cpDNA sequences are highly conserved and the genome can be divided into four different regions: large single copy (LSC) and small single copy (SSC), which are separated from each other by two large internal repeat regions. A cpDNA genome typically contains between 120 and 130 genes, mainly involved in photosynthesis, transcription, and translation. The cpDNA genome is usually between $107 \mathrm{kbp}$ (Cathaya argyrophylla, Pinaceae family) and $218 \mathrm{kbp}$ (Pelargonium, Geraniaceae family) in size. However, smaller cpDNA genomes are also common; for example, Apicomplexa genomes are around $30 \mathrm{kbp}$. On the other hand, the chromophore genome of Paulinella chromatophora is larger than some complete bacterial genomes, with $1022 \mathrm{kbp}$ due to the unique recent engulfing event. Chloroplast genome size is independent of nuclear genome size [16].

The evolution of cpDNA genes is slower than that of nuclear genes [17], but faster than that of mtDNA genes [18]. Many of today's algae and almost all land plants carry two identical copies of a large coding sequence called the large IR A and IR B regions (varying from $20 \mathrm{kbp}$ to $36 \mathrm{kbp}$ ), whose sequences may differ remarkably in individual species. In algae, the whole large IR has been lost multiple times during evolution [19]. In the parasitic and often nonphotosynthetic plants of Orobanchaceae family, the independent losses of one large IR region occur; Conopholis americana has the smallest cpDNA genome of land plants (45 kb) [20]. Loss of the large IR was also observed in some legumes (Papilionoideae subfamily, for example) [21]. Recently, it was found that, compared to single copy genes, synonymous substitution rates are on average 3.7-fold slower in chloroplast large IR genes (mainly coding for ribosomal, transfer RNAs, and ribosomal proteins). This may be due to the duplicative nature of the large IR, which reduces the substitution rate within these regions [22]. cpDNA rearrangements are more frequent when a large IR region is lost, suggesting that large IR regions are important for maintaining the conserved arrangement of cpDNA sequences [23]. In our analyses, we focused only on "short" IRs (6-60 bp) which are able to form cruciform structures. We analyzed these S-IRs in all sequenced cpDNA genomes to determine frequencies, localization, and similarities/differences.

\section{Materials and Methods}

2.1. Analyses of cpDNA Sequences. The set of 2,566 complete plastid cpDNA sequences were downloaded from the genome database of the National Center for Biotechnology Information (NCBI). We used the computational core of our DNA analyser software [24] modified to read NCBI identifiers of sequences from a text file and to download them. The parameters of analyses were size of S-IR 6 to $60 \mathrm{bp}$ and spacer size 0 to $10 \mathrm{bp}$, and maximally one mismatch was allowed. Analysis produced a separate list of S-IRs found in each of the 2,566 cpDNA sequences and an overall report for each selected group. Overall results for each species group contained a list of species with the size of its cpDNA sequence and the number of S-IRs found in that sequence. Our software also counted S-IRs grouped by their individual size (6-60 bp individually and the sum of S-IRs longer than $8 \mathrm{bp}, 10 \mathrm{bp}$, and $12 \mathrm{bp})$.

\subsection{Analysis of S-IRs around Annotated NCBI Features.} We downloaded the genome feature tables from the NCBI database along with the cpDNA sequences. We performed analysis of S-IR occurrence inside and around (before and after) recorded features. Features were grouped by their name stated in the feature table file. From this analysis we obtained a file with feature names and numbers of S-IRs found inside and around features for each group of species analyzed. Search for S-IRs took place in predefined feature neighborhoods (we used $\pm 100 \mathrm{bp}$; this figure is important for calculation of S-IR frequency in feature neighborhood) and inside feature boundaries. We calculated the amount of all S-IRs and those longer than 8, 10, and $12 \mathrm{bp}$ in regions before, inside, and after features. The categorization of an S-IR according to its overlap with a feature or feature neighborhood is demonstrated by the example shown in Supplementary Figure S1. Further processing was performed in Microsoft Excel.

2.3. Analyses of Similarities. Similarity among S-IRs was performed for those with abundant presence in the cpDNA genomes by Levenshtein algorithm, which counts distance between two strings according to the number of deletions, insertions, or substitutions required to transform source string into target string [25].

2.4. Phylogenetic Tree Construction. Exact taxid IDs of all analyzed groups (obtained from Taxonomy Browser via NCBI Taxonomy Database [26]) were downloaded to phyloT: a tree generator (http://phylot.biobyte.de) and a phylogenetic tree was constructed using function "Visualize in iTOL" in Interactive Tree of Life environment [27]. The resulting tree is shown in Supplementary Figure 2.

2.5. Statistical Analysis. Cluster dendrogram of S-IR frequency data (Supplementary Table S1) was made in R v. 3. 4. 3 (R Core Team, 2016) using the hclust function with the cluster method "ward.D2". The resulting cluster dendrogram is shown in Supplementary Figure S2. Principal component analysis (PCA) interactive plots were made in R with ggplot2 [28] and plotly [29]. The R code is available in Supplementary Code S1. Frequency of S-IRs (categorized by length) in individual species groups was used as input data, so one PCA plot was constructed for each species group to display intragroup variability.

\section{Results and Discussion}

3.1. General Statistics for cpDNA. cpDNAs are stored in the genome database in the three taxonomy groups (Protists, Plants, and others) and four subgroups (Apicomplexans, 
TABLE 1: Numbers and frequencies of S-IRs according to size.

\begin{tabular}{lcccccccc}
\hline IR size & $\begin{array}{c}\text { Amount in } \\
\text { dataset }\end{array}$ & $\begin{array}{c}\text { IR frequency } \\
\text { per 1000bp }\end{array}$ & IR size & $\begin{array}{c}\text { Amount in } \\
\text { dataset }\end{array}$ & $\begin{array}{c}\text { IR frequency } \\
\text { per 1000bp }\end{array}$ & $\begin{array}{c}\text { IR size } \\
\begin{array}{c}\text { Amount in } \\
\text { dataset }\end{array}\end{array} \begin{array}{c}\text { IR frequency } \\
\text { per 1000bp }\end{array}$ \\
\hline 6 & $10,351,040$ & 26.899 & 15 & 13,370 & 0.035 & 24 & 1,619 & 0.004 \\
\hline 7 & $4,157,127$ & 10.803 & 16 & 6,641 & 0.017 & 25 & 1,005 & 0.003 \\
\hline 8 & $1,656,101$ & 4.304 & 17 & 5,505 & 0.014 & 26 & 0.002 \\
\hline 10 & 637,184 & 1.656 & 18 & 3,595 & 0.009 & 27 & 1,231 & 460 \\
\hline 11 & 264,249 & 0.687 & 19 & 2,783 & 0.007 & 28 & 350 & 0.003 \\
\hline 12 & 113,649 & 0.295 & 20 & 2,676 & 0.007 & 29 & 0.001 \\
\hline 13 & 50,229 & 0.131 & 21 & 2,108 & 0.005 & 30 & 302 & 0.001 \\
\hline 14 & 27,833 & 0.072 & 22 & 3,090 & 0.008 & $>30$ & 1,105 & 0.004 \\
\hline
\end{tabular}

Green Algae, Plants, and others). However, the vast majority of sequences belong to the Plants subgroup $(2,278)$, compared to Apicomplexans (36) and Green Algae (107). Due to discrepancies in the number of sequenced cpDNA genomes in diverse groups (for example, the phylogenetically important group Euglenozoa has only 9 sequenced cpDNAs whereas Rosids and Asterids in the Pentapalae group [30] each have more than 400), we divided downloaded sequences into 21 phylogenetically related groups with a minimum of eight members in each group (see Supplementary Figure 2). This division allows us to observe detailed trends in S-IR frequency evolution across the Plant kingdom (from evolutionary oldest Bryophyta to Polypodiopsida, Acrogymnospermae, Basal Magnoliophyta, Magnoliidae, Alismatales, Dioscoreales, Liliales, Asparagales, Commelinids, Early-Diverging Eudicotyledons, Santalales, Saxifragales, Caryophyllales, to Asterids and Rosids). In total, we have analyzed 2,565 plastid genomes and, in addition, the chromatophore genome of amoeba Paulinella chromatophora. The length of cpDNA sequences (Table 1) varies from 11,348 bp (Pilostyles aethiopica, endoparasitic land plant which preserved only 17 chloroplast genes of the usual number of 116 cpDNA genes [16]) to 610,063 bp in Bulboplastis apyrenoidosa algae from the Rhodophyta division. Recently, a plastid DNA was described for red algae Corynoplastis japonica as the largest and most intron-rich plastid genome (1.13 Mbp) [31]. However, the majority of cpDNA genomes varied in the close interval between 120 and $150 \mathrm{kbp}$. The cpDNA genome of Paulinella chromatophore, which has a plastid genome from a different engulfment event estimated only 60 million years ago, is 1,021,616 bp [14], longer than the whole genomes of individual prokaryotic organisms. Aside from this unique organism, the longest cpDNAs are typical for Rhodophyta, Chlorophyta, and Zygnemophyceae, and the shortest for unicellular organisms in the phylum Euglenozoa (Figure 1). Length variability is generally correlated with evolutionary age. The largest variability is observed in the group Chlorophyta and Rhodophyta while the sizes of cpDNA in group Liliales and other land plants are relatively constant. The variability of length in higher plants is limited compared to lower plants (bryophyta, algae, etc.) (Figure 1). Contrary to the diverse sizes of cpDNA in ancient phylogenetic groups, the size of the cpDNA in phylogenetically newer groups is more limited with only a few exceptions. For example, $75 \%$ of all 522 sequenced cpDNA genomes in clade Rosids are in the size interval of 159,441 to $160,886 \mathrm{bp}$, differing by less than $1 \%$.

3.2. Analyses of Short Inverted Repeats. The total number of nucleotides in the 2,566 plastid genomes analyzed is $384,975,139 \mathrm{bp}$ and we found 17,326,953 S-IRs. The average frequency is 47 (17-81) S-IR/kbp for green algae and 34 (29-59) S-IR/kbp for land plants. The differences between organisms are significant; $50 \%$ of cpDNAs have a frequency of 40 to $45 \mathrm{~S}$-IR/kbp, but S-IR frequencies range from $26 \mathrm{~S}$ IR/kbp in unicellular green algae of the order Mamiellales Ostreococcus tauri, while other green algae, specifically of the order Volvocaceae Pleodorina starrii have a frequency of $191.98 \mathrm{~S}-\mathrm{IR} / \mathrm{kbp}$. Ostreococcus tauri is a member of global oceanic picoplankton and is the smallest described freeliving eukaryote with very a compact genome. Pleodorina starrii is another alga which is composed of 32 or 64 biflagellate cells. Values of S-IR frequencies for all groups are shown in Figure 2. The highest S-IR frequencies are in the groups Euglenozoa (67.87 S-IR/kbp) and Bryophyta (67.24 S-IR/kbp) followed by Chlorophyta (60.95 S-IR/kbp) and Rhodophyta (59 S-IR/kbp) and the lowest S-IR frequencies are in the groups Polypodiopsida (37.65 S-IR/kbp) followed by Basal Magnoliophyta (40.11 S-IR/kbp), Magnoliidae (40.14 $\mathrm{S}-\mathrm{IR} / \mathrm{kbp}$ ), and Commelinids (40.63 S-IR/kbp). Statistics and evaluation for all groups are provided in Supplementary Table S2.

Comparing S-IRs in individual organisms and subgroups shows a general decrease in frequency with increasing S-IR length, except for S-IRs 15, 22, 24, or 27 bp long, which are present more often than expected by approximation from neighboring values (Table 1). Similar selective abundance according to length has also been observed for mtDNAs, but only for S-IR lengths 24 and $30 \mathrm{bp}$. Both 24 and $30 \mathrm{bp}$ long S-IRs are also more frequent than expected in cpDNA sequences, but there is very strong relative abundance also for 15,22 , and $27 \mathrm{bp} \mathrm{S}$-IRs. We investigated if the S-IRs abundantly present in cpDNA genomes are similar using analyses of similarity by Levenshtein distance (Supplementary Data 1). We used two different conditions for the 


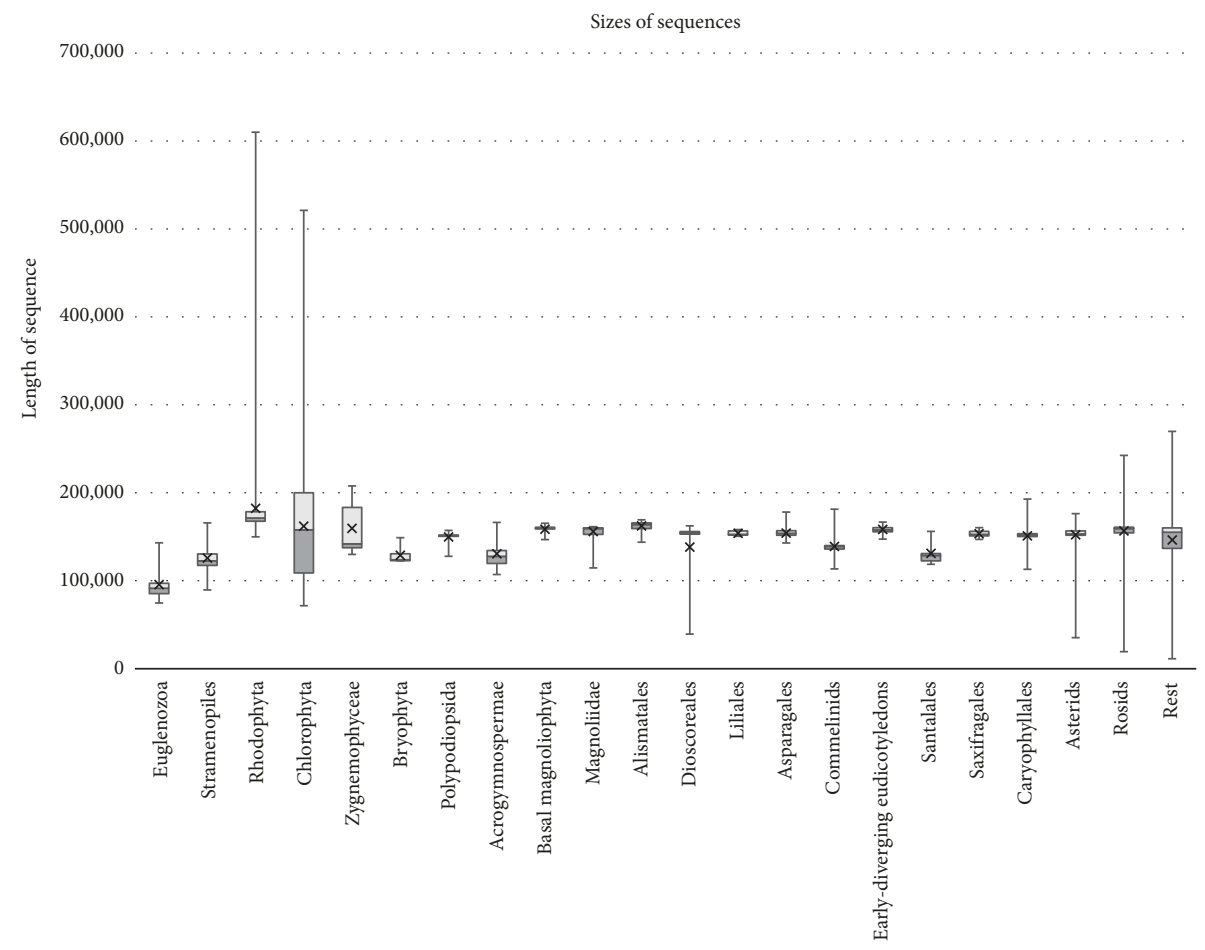

Figure 1: Variability of length of cpDNAs. Box plots show sequence length interquartile ranges for different species groups. The whiskers represent the minimum and maximum values.

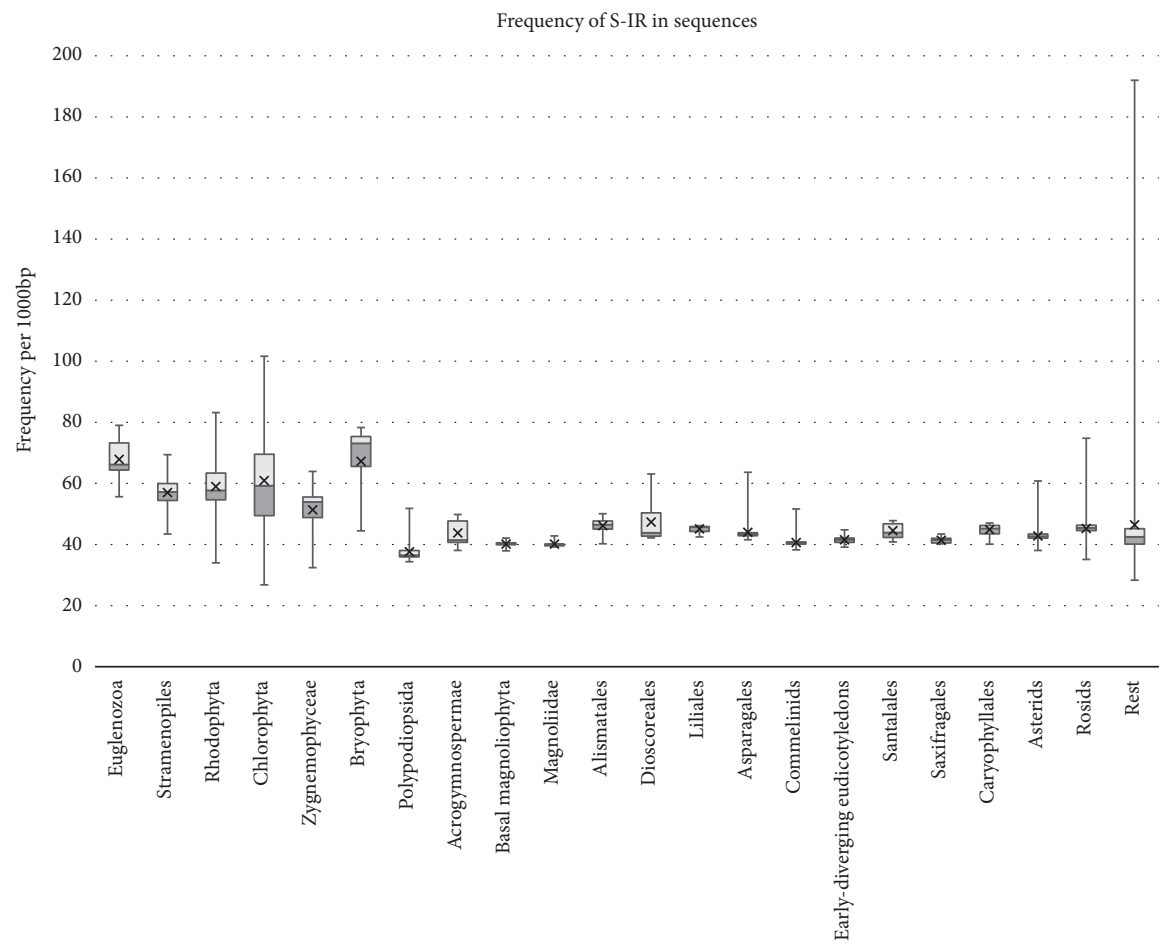

FIgURE 2: Frequency of S-IRs in mtDNAs for subgroups and numbers of mtDNAs. The box plot shows the interquartile ranges of S-IR frequencies per $1000 \mathrm{bp}$ in different species groups. Whiskers represent the minimum and maximum values. 
comparison, identity and Levenshtein distance 2 or less. These results show that especially longer S-IR sequences are shared only for a few phylogenetic groups; on the other hand shorter S-IR sequences are often shared across several phylogenetic groups (Supplementary Data 1). Our results show that $27 \mathrm{bp}$ S-IRs are present most often as the sequences AAATTCTTTTATTTTAGATAGAAGAAA and ACATTCTTTTATTTTAGATAGAAGAAA (both 320 times); the next most abundant sequence was present in all genomes only 34 times. Both sequences are identical except for one nucleotide; therefore for Levenshtein distance 2 and less we found AAATTCTTTTATTTTAGATAGAAGAAA sequence 655 times, followed by TATAAGTGAACTAGATAAAACGGAATC sequence 49 times. For 22 bp long $\mathrm{S}$-IRs, the sequence AGAGCTCGGATCGAATCGGTAT is present 414 times; the next most abundant sequence was present only 89 times in all genomes. For Levenshtein distance 2 and less we found AGAGCTCGGATCGAATCGGTAT sequence in 590 cases, followed by TAATTGAAGTAAGAAGTCTCCC sequence 240 times. For 15 bp long SIRs, the most common sequences were ATAAAAGAAAGAAGA and AAAAAAGAAAGAAGA (presented 1,346 and 1,341 times, respectively), and the next most abundant sequence was present only 370 times in all genomes. Both most abundant sequences are identical except for one nucleotide; therefore for Levenshtein distance 2 and less we found ATAAAAGAAAGAAGA 2,702 times, followed by AAAAAAAAAGAAAGA 1,272 times.

The detailed results of S-IR frequencies for all groups are summarized in Table 2. The most common longest S-IRs varied from $17 \mathrm{bp}$ (in Commelinids) to $32 \mathrm{bp}$ (in Bryophyta). The most common longest S-IR in vascular plants (Tracheophyta) (24 bp) was found in Asparagales. We also found 1,105 SIRs longer than $30 \mathrm{bp}$ in cpDNA genomes (range 31-100 bp), but they constituted less than $0.01 \%$ of the total number of 17,326,953 S-IRs identified.

3.3. Comparison of S-IR Frequencies according to Sequence Annotations. The NCBI genome database contains annotations for cpDNA sequences. The best described are gene $(343,857)$, CDS $(226,783)$, tRNA $(91,586)$, exon $(36,345)$, rRNA $(18,719)$, and intron (11,028). Numbers of annotations at the time of analysis are given in Supplementary Table S3. To compare S-IR frequencies at different locations we used the most commonly described location "gene" as a standard for comparison with other locations. There are significant differences in S-IR frequency in diverse segments of cpDNAs. The largest relative increase of S-IR frequency is for stemloop sequences (12.8-times higher) followed by regulatory $(3.2 \mathrm{x})$, intron $(2.4 \mathrm{x})$, and misc sequences $(2.7 \mathrm{x})$ (Figure 3 ). The presence of the "large internal repeat region" is typical for higher plants. The difference between S-IR frequency in the large internal repeat regions and gene regions is only 1.7-fold, whereas S-IRs are 4.6-fold higher in the sequences surrounding these features and the frequency of $12 \mathrm{bp} \mathrm{S-}$ IRs and longer is 7.6 times higher before the repeat region compared to gene regions. Another interesting finding is the presence of S-IRs in introns; while S-IRs are abundant in introns, S-IR frequencies are significantly reduced in exon sequences that neighbor introns (both $100 \mathrm{bp}$ before and after introns). We observed significantly reduced S-IR frequencies in and around rRNAs compared to gene locations, especially for $12 \mathrm{bp}$ and longer S-IRs. The opposite effect is seen for tRNA sequences. Raw data are in Supplementary Tables S4 and S5.

Based on the data from S-IR analyses we produced a cluster dendrogram of individual groups (Supplementary Figure 2). The real phylogenetic tree is fairly consistent with this cluster dendrogram. Very interesting is the proximity of Euglenozoa and Bryophyta clades. However, this may be due the fact that both groups contain only a small number of accessible sequenced genomes (only 9 and 8 cpDNA genomes are available for Euglenozoa and Bryophyta, respectively).

Based on PCA analysis (Supplementary Data 2.html) of SIR frequencies data (Supplementary Table S2), some interesting facts emerged. The most interesting findings in individual groups from our point of view are shortly commented with appropriate references in the following bullet paragraphs; for details please check interactive graphs (Supplementary Data 2.html):

(i) In Rosids, the cpDNA of the holoparasitic plant Cytinus hypocistis was sequenced recently [20] and PCA analysis of S-IR frequency revealed a very unusual profile in comparison with the rest of the group (Supplementary Data 2.html). Cytinus hypocistis has an extremely small cpDNA genome $(19.4 \mathrm{~kb})$ with only 23 genes and no large IR-A or IR-B regions [20]. On the other hand, Cytinus hypocistis has the highest S-IR/kbp cpDNA value from all 522 analyzed Rosids (78.81 S-IR/kbp).

(ii) In Asterids, the most divergent S-IR frequencies in cpDNA include two species of the family Orobanchaceae (Phelipanche ramosa and Phelipanche purpurea), which are nonphotosynthetic flowering plants. Their S-IR frequencies are unusually high in comparison to the rest of the Asterids.

(iii) In Caryophyllales, the flytrap Dionaea muscipula has an unusually low S-IR frequency in cpDNA.

(iv) In Early-Diverging Eudicotyledons, Gymnospermium microrrhynchum has the highest S-IR frequency, especially for S-IRs longer than $12 \mathrm{bp}$.

(v) In Commelinids, Carex neurocarpa has the highest SIR frequency in cpDNA. In Asparagales, Cypripedium formosanum (endemic orchid of Taiwan) has a very high S-IR frequency in cpDNA.

(vi) In Liliales, all three PCA clusters are very well distinguished from each other. In Dioscoreales, Burmannia oblonga has the highest S-IR frequency in cpDNA.

(vii) In Alismatales, the aquatic plant Najas flexilis has a low S-IR frequency in cpDNA in comparison to the rest of the group. The plastid genome of Najas flexilis presents some anomalous modifications (reduced size of a small single copy region, eleven $n d h$ gene losses) [21]. 
TABLE 2: cpDNA sizes and S-IR frequencies and lengths.

\begin{tabular}{|c|c|c|c|c|c|c|}
\hline Group name & $\begin{array}{l}\text { Number of } \\
\text { seq. }\end{array}$ & $\begin{array}{l}\text { Median size } \\
{[\mathrm{bp}]}\end{array}$ & Shortest sequence & Longest sequence & $\begin{array}{l}\text { IR/kbp } \\
\text { Mean } \\
\text { range }\end{array}$ & $\begin{array}{c}\text { Longest S-IR } \\
\text { for } 50 \% \text { of } \\
\text { seq. [bp] }\end{array}$ \\
\hline \multirow[t]{2}{*}{ Euglenozoa } & \multirow[t]{2}{*}{9} & \multirow[t]{2}{*}{91,616} & $\begin{array}{c}\text { Monomorphina } \\
\text { aenigmatica }\end{array}$ & Euglena gracilis & 68 & \multirow[t]{2}{*}{18} \\
\hline & & & $(74,746$ bp $)$ & $(143,171$ bp $)$ & $56-79$ & \\
\hline \multirow[t]{2}{*}{ Stramenopiles } & \multirow[t]{2}{*}{37} & \multirow[t]{2}{*}{122,660} & $\begin{array}{c}\text { Aureococcus } \\
\text { anophagefferens }\end{array}$ & $\begin{array}{l}\text { Cylindrotheca } \\
\text { closterium }\end{array}$ & 57 & \multirow[t]{2}{*}{25} \\
\hline & & & $(89,599$ bp $)$ & $(165,809$ bp $)$ & $43-69$ & \\
\hline \multirow[t]{2}{*}{ Rhodophyta } & \multirow[t]{2}{*}{60} & \multirow[t]{2}{*}{171,284} & $\begin{array}{c}\text { Cyanidioschyzon } \\
\text { merolae }\end{array}$ & $\begin{array}{l}\text { Bulboplastis } \\
\text { apyrenoidosa }\end{array}$ & 59 & \multirow[t]{2}{*}{19} \\
\hline & & & $(149,987$ bp $)$ & $(610,063$ bp $)$ & $34-83$ & \\
\hline Chlorophyta & 90 & 157,916 & $\begin{array}{l}\text { Ostreococcus tauri } \\
\quad(71,666 \mathrm{bp})\end{array}$ & $\begin{array}{l}\text { Floydiella terrestris } \\
\qquad(521,168 \mathrm{bp})\end{array}$ & $\begin{array}{c}61 \\
27-102\end{array}$ & 27 \\
\hline Zygnemophyceae & 11 & 142,017 & $\begin{array}{l}\text { Spirogyra maxima } \\
\quad(129,954 \mathrm{bp})\end{array}$ & $\begin{array}{l}\text { Cosmarium botrytis } \\
(207,850 \mathrm{bp})\end{array}$ & $\begin{array}{c}51 \\
32-64\end{array}$ & 24 \\
\hline Bryophyta & 8 & 123,868 & $\begin{array}{c}\text { Syntrichia ruralis } \\
(122,630 \mathrm{bp})\end{array}$ & $\begin{array}{c}\text { Takakia lepidozioides } \\
(149,016 \mathrm{bp})\end{array}$ & $\begin{array}{c}67 \\
44-78\end{array}$ & 32 \\
\hline Polypodiopsida & 49 & 151,126 & $\begin{array}{l}\text { Diplazium unilobum } \\
\qquad(127,840 \mathrm{bp})\end{array}$ & $\begin{array}{l}\text { Lygodium japonicum } \\
\qquad(157,260 \mathrm{bp})\end{array}$ & $\begin{array}{c}38 \\
34-52\end{array}$ & 18 \\
\hline Acrogymnospermae & 85 & 127,659 & $\begin{array}{c}\text { Cathaya argyrophylla } \\
\qquad(107,122 \mathrm{bp})\end{array}$ & $\begin{array}{c}\text { Macrozamia } \\
\text { mountperriensis } \\
(166,341 \mathrm{bp})\end{array}$ & $\begin{array}{c}44 \\
38-50\end{array}$ & 23 \\
\hline Basal magnoliophyta & 13 & 159,881 & $\begin{array}{c}\text { Schisandra chinensis } \\
\quad(146,859 \mathrm{bp})\end{array}$ & $\begin{array}{l}\text { Trithuria inconspicua } \\
\qquad(165,389 \mathrm{bp})\end{array}$ & $\begin{array}{c}40 \\
38-42\end{array}$ & 18 \\
\hline Magnoliidae & 41 & 159,443 & $\begin{array}{l}\text { Cassytha filiformis } \\
\text { (114,622 bp) }\end{array}$ & $\begin{array}{c}\text { Piper kadsura } \\
(161,486 \text { bp })\end{array}$ & $\begin{array}{c}40 \\
39-43\end{array}$ & 18 \\
\hline Alismatales & 14 & 163,856 & $\begin{array}{c}\text { Zostera marina } \\
(143,877 \mathrm{bp})\end{array}$ & $\begin{array}{l}\text { Wolffiella ryophyte } \\
\qquad(169,337 \mathrm{bp})\end{array}$ & $\begin{array}{c}46 \\
40-50\end{array}$ & 22 \\
\hline Dioscoreales & 10 & 154,205 & $\begin{array}{l}\text { Burmannia oblonga } \\
\qquad(39,386 \mathrm{bp})\end{array}$ & $\begin{array}{c}\text { Tacca } \\
\text { leontopetaloides } \\
(162,477 \mathrm{bp})\end{array}$ & $\begin{array}{c}47 \\
42-63\end{array}$ & 22 \\
\hline Liliales & 41 & 152,677 & $\begin{array}{c}\text { Amana wanzhensis } \\
\quad(150,576 \mathrm{bp})\end{array}$ & $\begin{array}{l}\text { Heloniopsis tubiflora } \\
\qquad(158,229 \mathrm{bp})\end{array}$ & $\begin{array}{c}45 \\
42-46\end{array}$ & 18 \\
\hline Asparagales & 125 & 153,953 & $\begin{array}{l}\text { Oberonia japonica } \\
\qquad(142,996 \mathrm{bp})\end{array}$ & $\begin{array}{l}\text { Cypripedium } \\
\text { formosanum } \\
(178,131 \mathrm{bp})\end{array}$ & $\begin{array}{c}44 \\
42-64\end{array}$ & 24 \\
\hline Commelinids & 290 & 139,171 & $\begin{array}{l}\text { Aegilops cylindrica } \\
\qquad(113,490 \mathrm{bp})\end{array}$ & $\begin{array}{l}\text { Carex neurocarpa } \\
\qquad(181,397 \text { bp })\end{array}$ & $\begin{array}{c}41 \\
38-52\end{array}$ & 17 \\
\hline $\begin{array}{l}\text { Early-diverging } \\
\text { eudicotyledons }\end{array}$ & 49 & 157,817 & $\begin{array}{l}\text { Kingdonia uniflora } \\
\text { (147,378 bp) }\end{array}$ & $\begin{array}{l}\text { Berberis koreana } \\
(166,758 \mathrm{bp})\end{array}$ & $\begin{array}{c}42 \\
39-45\end{array}$ & 19 \\
\hline Santalales & 9 & 128,744 & $\begin{array}{l}\text { Schoepfia } \\
\text { jasminodora } \\
(118,743 \mathrm{bp})\end{array}$ & $\begin{array}{l}\text { Erythropalum } \\
\text { scandens } \\
(156,154 \mathrm{bp})\end{array}$ & $\begin{array}{c}45 \\
41-48\end{array}$ & 18 \\
\hline Saxifragales & 10 & 152,692 & $\begin{array}{l}\text { Phedimus } \\
\text { takesimensis } \\
(147,048 \mathrm{bp})\end{array}$ & $\begin{array}{l}\text { Liquidambar } \\
\text { formosana } \\
(160,410 \mathrm{bp})\end{array}$ & $\begin{array}{c}41 \\
40-43\end{array}$ & 20 \\
\hline Caryophyllales & 32 & 151,686 & $\begin{array}{c}\text { Carnegiea gigantea } \\
(113,064 \mathrm{bp})\end{array}$ & $\begin{array}{l}\text { Drosera rotundifolia } \\
\quad(192,912 \text { bp })\end{array}$ & $\begin{array}{c}45 \\
40-47\end{array}$ & 19 \\
\hline
\end{tabular}


TABLE 2: Continued.

\begin{tabular}{|c|c|c|c|c|c|c|}
\hline Group name & $\begin{array}{l}\text { Number of } \\
\text { seq. }\end{array}$ & $\begin{array}{l}\text { Median size } \\
{[\mathrm{bp}]}\end{array}$ & Shortest sequence & Longest sequence & $\begin{array}{l}\mathrm{IR} / \mathrm{kbp} \\
\text { Mean } \\
\text { range }\end{array}$ & $\begin{array}{c}\text { Longest S-IR } \\
\text { for } 50 \% \text { of } \\
\text { seq. [bp] }\end{array}$ \\
\hline \multirow[t]{2}{*}{ Asterids } & \multirow[t]{2}{*}{398} & \multirow[t]{2}{*}{153,377} & Monotropa hypopitys & $\begin{array}{l}\text { Adenophora } \\
\text { divaricata }\end{array}$ & 43 & \multirow[t]{2}{*}{19} \\
\hline & & & $(35,336 \mathrm{bp})$ & $(176,331 \mathrm{bp})$ & $38-61$ & \\
\hline \multirow[t]{2}{*}{ Rosids } & \multirow[t]{2}{*}{522} & \multirow[t]{2}{*}{159,441} & Cytinus hypocistis & $\begin{array}{l}\text { Pelargonium } \\
\text { transvaalense }\end{array}$ & 45 & \multirow[t]{2}{*}{20} \\
\hline & & & $(19,400 \mathrm{bp})$ & $(242,575$ bp $)$ & $35-75$ & \\
\hline Rest & 662 & 155,196 & $\begin{array}{c}\text { Pilostyles aethiopica } \\
\qquad(11,348)\end{array}$ & $\begin{array}{c}\text { Pleodorina starrii } \\
(269,857)\end{array}$ & $\begin{array}{c}46 \\
28-192\end{array}$ & 20 \\
\hline
\end{tabular}

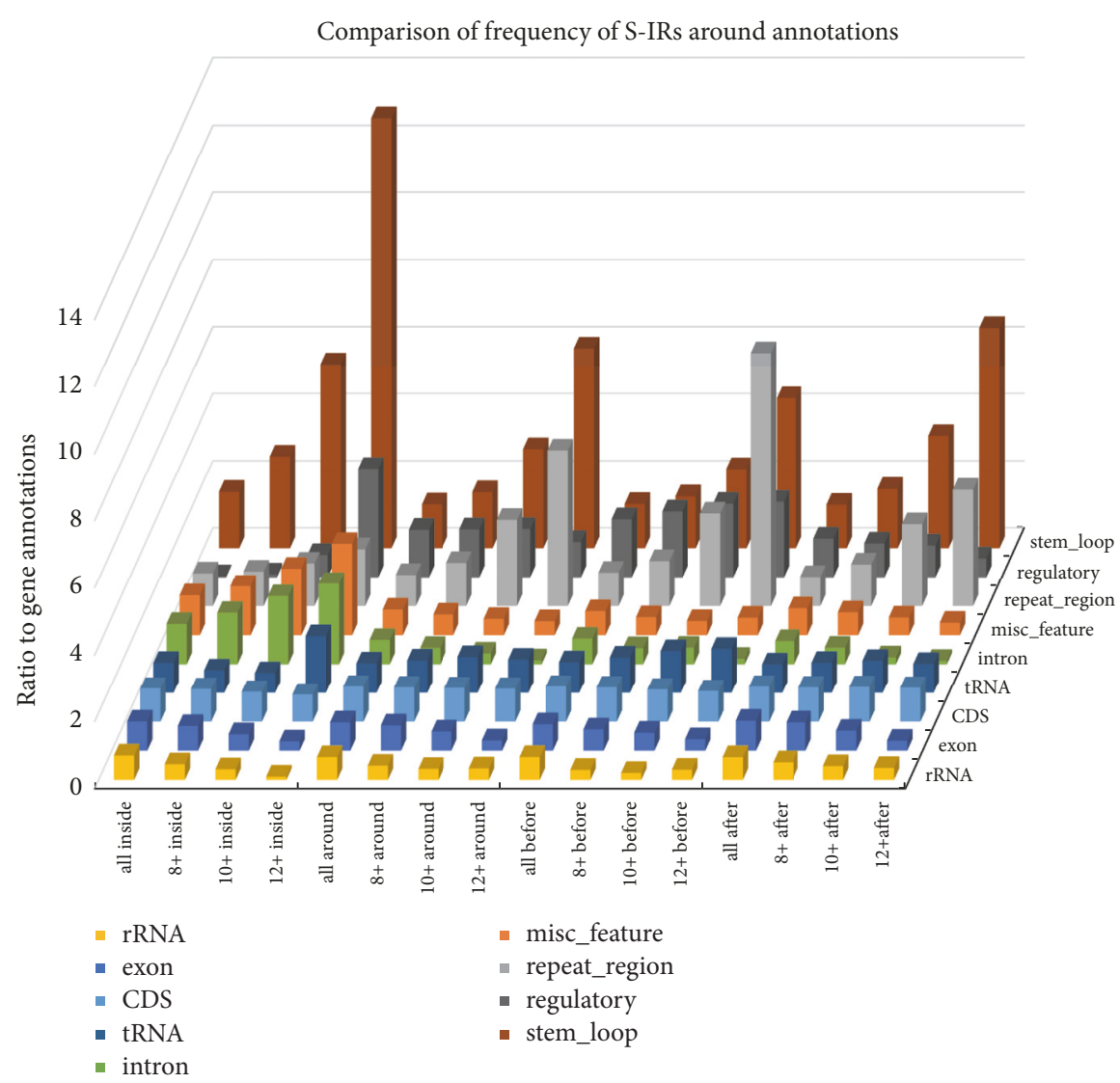

FIGURE 3: Differences in S-IR frequency by DNA locus. The chart shows S-IR frequencies per 1000 bp between "gene" annotation and other annotated locations from the NCBI database. We analyzed frequencies of all S-IRs (all) and of S-IRs with lengths $8 \mathrm{bp}$ and longer ( $8+$ ), $10 \mathrm{bp}$ and longer (10+), and $12 \mathrm{bp}$ and longer (12+) within annotated locations (inside) and before (100 bp) and after (100 bp) annotated locations.

(viii) In Magnoliidae, Cassytha filiformis and two species of pepper vine (Piper kadsura and Piper cenocladum) have the most divergent pattern of S-IR in cpDNA (higher frequencies of S-IRs) compared with the rest of group.

(ix) In Basal Magnoliophyta, Trithuria inconspicua (endemic aquatic herb of New Zealand) has the lowest $\mathrm{S}$-IR frequency in cpDNA in comparison with the rest of the group (especially for S-IRs longer than $10 \mathrm{bp}$ ).

(x) In acrogymnospermae, all three PCA clusters are very well distinguished from each other (Supplementary
Data 2). In Polypodiopsida, two species of class Equisetopsida (Equisetum hyemale and Equisetum arvense) have a very high frequency of S-IRs compared with other species in this group.

(xi) In Bryophyta, two species (Sphagnum palustre and Takakia lepidozioides) have very low S-IR frequencies in cpDNA in comparison with the rest of the group.

(xii) In Zygnemophyceae, Spirogyra maxima has the highest frequency of S-IR in cPDNA (for S-IRs longer than $12 \mathrm{bp}$ there is more than 10 -fold enrichment in comparison with the other species in the group). 
(xiii) In Chlorophyta, four species of family Ulvaceae (Ulva fasciata, Ulva linza, Ulva prolifera, and Ulva flexuosa) have very high frequencies of S-IRs in comparison with the rest of the group.

(xiv) In Rhodophyta, the strangest pattern of S-IR frequency in cpDNA was found in Cyanidioschyzon merolae, a small unicellular haploid red alga adapted to hot spring environment with high sulfur acidic content. Cyanidioschyzon merolae has only one chloroplast and mitochondria. After detailed analysis we have found that cpDNA of Cyanidioschyzon merolae has an extremely low content of S-IRs in comparison to the rest of the Rhodophyta group.

(xv) In Stramenopiles, Aureococcus anophagefferens (unicellular alga with only one chloroplast and mitochondrion) and Aureoumbra lagunensis have the lowest SIR frequency in cpDNA in comparison with the rest of the group. In Aureococcus anophagefferens and Aureoumbra lagunensis the large IR regions were lost [22].

(xvi) In Euglenozoa, Monomorphina aenigmatica has the highest S-IR frequency and the plastid genome of this species is AT rich (70.6\%) and contains 53 intron insertion sites, of which 41 were found to be shared with other euglenids [23].

DNA cruciforms are formed by S-IRs and with their important roles in replication, transcription and DNA stability it is not surprising that S-IRs are also present in cpDNA genomes. Analyses of mtDNA genomes revealed that S-IR sequences are abundant and nonrandomly distributed in the mitochondrial genomes of all living organisms, with particular abundance in regulatory regions such as replication origin and D-loop region [12]. Here, we analyzed all available cpDNA genomes for the presence of S-IRs capable of forming cruciform structures. Our results show that the typical maximal S-IR length in cpDNA varied from $17 \mathrm{bp}$ (Commelinids) to $32 \mathrm{bp}$ (Bryophyta). Interestingly, substantial numbers of longer S-IRs are detected in some cpDNAs. While the mean frequency of S-IR was $\sim 45$ IRs/kbp, the frequency was remarkably higher in some plastid genomes. In 13 plastid genomes, the frequency was higher than $100 \mathrm{~S}-\mathrm{IR} / \mathrm{kbp}$, most of these genomes were from Apicomplexa, but also red algae Choreocolax polysiphoniae, which has reduced gene regions [32]. These organisms typically contain an AT-rich relict plastid which functions in fatty acid biosynthesis, heme biosynthesis, iron-sulfur cluster synthesis, and isoprenoid biosynthesis, but they are deficient in photosynthetic abilities [33]. Long IRs (about 20-36 kbp long) in cpDNA can help stabilize the rest of the chloroplast genome and prevent gene loss-and-gain rearrangements [34]. Interestingly, these longer IRs are surrounded by short S-IRs. While the difference between S-IR frequency in the repeat regions and gene regions is relatively small, the frequency of $12 \mathrm{bp}$ and longer $\mathrm{S}$-IRs in the surrounding sequences is 7.6 times higher before the repeat region. It is likely that S-IRs in cpDNA also form cruciform structures in vivo and these are targets for binding of specific proteins (our hypothesis is based on cruciform functions and preferential protein binding to cruciforms in human and other model organisms). Some information is available to support this concept in plants; ribosomal protein S16 (RPS16) binds to cruciform DNA and is targeted to the chloroplast, indicating the possibility of RPS16-cruciform cpDNA interactions and regulation [35]. Moreover, S-IRs were found to be highly enriched in stem-loop sequences, which have an important regulatory function in cpDNAs.

\section{Conclusions}

Chloroplasts, as basic organelles for algae and plants, are fundamental for life due to their oxygen management. In this paper, we analyzed all 2,566 sequenced cpDNA by "palindrome analyser". We described the basic parameters of cpDNA including the frequency and localization of SIRs able to form cruciform structures. Interestingly, the frequency of S-IR does not decrease for S-IRs 15, 22, 24, or $27 \mathrm{bp}$ long. These results point to the importance of specific S-IRs in cpDNA genomes. Moreover, comparison by Levenshtein distance of S-IR similarities showed that a limited number of sequences are shared in the majority of cpDNA S-IRs. S-IRs are not located randomly, but are lengthdependently enriched in specific locations, including the repeat region, stem, introns, and tRNA regions of cpDNA genomes. The highest enrichment was found for $12 \mathrm{bp}$ and longer S-IRs in the stem-loop region, followed by $12 \mathrm{bp}$ and longer S-IRs located before the repeat region. These data showing nonrandom and conserved arrangements of S-IRs in chloroplast genomes indicate the potential importance of $\mathrm{S}$-IRs in basic biological processes within chloroplasts.

\section{Data Availability}

All data are freely accessible in the paper and in supporting materials.

\section{Conflicts of Interest}

The authors declare that there are no conflicts of interest regarding the publication of this paper.

\section{Acknowledgments}

The authors would like to thank Dr. Philip J. Coates for proofreading and editing the manuscript. This work was supported by the Grant Agency of the Czech Republic [18-15548S]; by project SGS11/PrF/2018 financed by University of Ostrava; and by the SYMBIT project Reg. no. CZ.02.1.01/0.0/0.0/15_003/0000477 financed from the ERDF.

\section{Supplementary Materials}

Supplementary Figure S1: neighborhood of an annotated feature. Example of possible S-IR occurrence around features and its classification: (a) an S-IR overlapping only partially with a feature is considered to be in near neighborhood; (b) an S-IR overlapping fully with a feature is therefore considered to be inside; (c) an S-IR is not considered to be 
in near neighborhood because it is not fully overlapping with either a feature or its neighborhood. Supplementary Figure 2: phylogenetic tree of all inspected organisms with chloroplast genome made using iTOL. Subgroups are highlighted by different colors. From left counterclockwise: Rosids (red, 522 species); Asterids (blue, 398 species); Caryophyllales (dark green, 32 species); Saxifragales (yellow, 10 species); Santalales (purple, 9 species); Early-Diverging Eudicotyledons (green, 49 species); Commelinids (red, 290 species); Asparagales (blue, 125 species); Liliales (yellow, 41 species); Dioscoreales (purple, 10 species); Alismatales (dark green, 14 species); Magnoliidae (orange, 41 species); Basal Magnoliophyta (green, 13 species); Acrogymnospermae (red, 85 species); Polypodiopsida (green, 49); Bryophyta (orange, 8 species); Zygnemophyceae (red, 11 species); Chlorophyta (purple, 90 species); Rhodophyta (green, 60 species); Stramenopiles (orange, 37 species); Euglenozoa (blue, 9 species). Supplementary Code S1: method for construction of interactive PCA plots from S-IR data by R (version 3.4.0). Referred Excel input for this analysis was values from even S-IR length columns of Supplementary Table S1. Supplementary Table S1: incidence of S-IRs. This table represents ratio of presence of $\mathrm{S}$-IRs by their length. Values were calculated by the following formula: number of sequences containing at least one S-IR of given length in a subgroup/total number of sequences in a subgroup. For example, in Alismatales subgroup, there is a total of 14 S-IR sequences, 9 of those sequences have S-IRs of length 24, and thus 9 / $14=0.64$. Supplementary Table S2: statistical evaluation of results. This table contains statistical data about groups of sequences. Row denoted usual longest SIR contains length of S-IR that is present in roughly half of the sequences of that group; see Table S3. Supplementary Table S3: feature amounts and length. This table shows amounts of annotated features in all downloaded sequences and their length. Supplementary Data 1: analysis of S-IR similarity for lengths $15,22,24$, and 27. The first four sheets group identical S-IRs from all cpDNA sequences. The last four sheets group S-IRs that are similar, based on Levenshtein distance of 2 or less. The upper part of each sheet contains the 20 most abundant S-IRs identified by rank. Lower parts of the sheets contain incidence for given S-IRs by rank in different groups of species. Supplementary Data 2.html: PCA plots: interactive PCA plots intuitively represent differences in cpDNA S-IR frequencies of all main groups and intradifferences of cpDNA S-IR frequencies between organisms of each subgroup. Organisms with the most distinct patterns of S-IR frequencies in their cpDNA are always more distant from the middle of the plot. (Supplementary Material)

\section{References}

[1] D. A. Gordenin, K. S. Lobachev, N. P. Degtyareva, A. L. Malkova, E. Perkins, and M. A. Resnick, "Inverted DNA repeats: A source of eukaryotic genomic instability," Molecular and Cellular Biology, vol. 13, no. 9, pp. 5315-5322, 1993.

[2] C. E. Pearson, H. Zorbas, G. B. Price, and M. ZannisHadjopoulos, "Inverted repeats, stem-loops, and cruciforms: Significance for initiation of DNA replication," Journal of Cellular Biochemistry, vol. 63, no. 1, pp. 1-22, 1996.
[3] V. Brázda, R. C. Laister, E. B. Jagelská, and C. Arrowsmith, "Cruciform structures are a common DNA feature important for regulating biological processes," BMC Molecular Biology, vol. 12, article 33, 2011.

[4] M. S. Z. Horwttz and L. A. Loeb, "An E. coli promoter that regulates transcription by DNA superhelix-induced cruciform extrusion," Science, vol. 241, no. 4866, pp. 703-705, 1988.

[5] A. S. Bradley, Z. Baharoglu, A. Niewiarowski, B. Michel, and I. R. Tsaneva, "Formation of a stable RuvA protein double tetramer is required for efficient branch migration in vitro and for replication fork reversal in vivo," The Journal of Biological Chemistry, vol. 286, no. 25, pp. 22372-22383, 2011.

[6] M. Zannis-Hadjopoulos, W. Yahyaoui, and M. Callejo, "14-3-3 Cruciform-binding proteins as regulators of eukaryotic DNA replication," Trends in Biochemical Sciences, vol. 33, no. 1, pp. 44-50, 2008.

[7] E. B. Jagelská, H. Pivoňková, M. Fojta, and V. Brázda, “The potential of the cruciform structure formation as an important factor influencing p53 sequence-specific binding to natural DNA targets," Biochemical and Biophysical Research Communications, vol. 391, no. 3, pp. 1409-1414, 2010.

[8] V. Brázda, J. Čechová, M. Battistin et al., "The structure formed by inverted repeats in p53 response elements determines the transactivation activity of p53 protein," Biochemical and Biophysical Research Communications, vol. 483, no. 1, pp. 516-521, 2017.

[9] M. Bracale, M. G. Galli, C. Savini, and M. E. Bianchi, "Specific interaction of plant HMG-like proteins with cruciform DNA," Journal of Experimental Botany, vol. 45, no. 10, pp. 1493-1496, 1994.

[10] M.-L. Weng, J. C. Blazier, M. Govindu, and R. K. Jansen, "Reconstruction of the ancestral plastid genome in geraniaceae reveals a correlation between genome rearrangements, repeats, and nucleotide substitution rates," Molecular Biology and Evolution, vol. 31, no. 3, pp. 645-659, 2014.

[11] X. Yi, L. Gao, B. Wang, Y.-J. Su, and T. Wang, "The complete chloroplast genome sequence of cephalotaxus oliveri (cephalotaxaceae): Evolutionary comparison of cephalotaxus chloroplast DNAs and insights into the loss of inverted repeat copies in gymnosperms," Genome Biology and Evolution, vol. 5, no. 4, pp. 688-698, 2013.

[12] J. Čechová, J. Lýsek, M. Bartas, and V. Brázda, "Complex analyses of inverted repeats in mitochondrial genomes revealed their importance and variability," Bioinformatics, vol. 34, no. 7, pp. 1081-1085, 2018.

[13] P. E. Jensen and D. Leister, "Chloroplast evolution, structure and functions," F1000Prime Reports, vol. 6, 2014.

[14] E. C. M. Nowack, M. Melkonian, and G. Glöckner, "Chromatophore Genome Sequence of Paulinella Sheds Light on Acquisition of Photosynthesis by Eukaryotes," Current Biology, vol. 18, no. 6, pp. 410-418, 2008.

[15] J. M. Archibald, “The Puzzle of Plastid Evolution," Current Biology, vol. 19, no. 2, pp. R81-R88, 2009.

[16] D. Henry, L. Choun-Sea, Y. Ming, and C. Wan-Jung, "Chloroplast genomes: diversity, evolution, and applications in genetic engineering," Genome Biology, vol. 17, article 134, 2016.

[17] J.-H. Xu, Q. Liu, W. Hu, T. Wang, Q. Xue, and J. Messing, "Dynamics of chloroplast genomes in green plants," Genomics, vol. 106, no. 4, pp. 221-231, 2015.

[18] K. H. Wolfe, W. H. Li, and P. M. Sharp, "Rates of nucleotide substitution vary greatly among plant mitochondrial, chloroplast, and nuclear DNAs," Proceedings of the National Acadamy 
of Sciences of the United States of America, vol. 84, no. 24, pp. 9054-9058, 1987.

[19] M. Turmel, C. Otis, and C. Lemieux, "Divergent copies of the large inverted repeat in the chloroplast genomes of ulvophycean green algae," Scientific Reports, vol. 7, no. 1, 2017.

[20] S. Wicke, K. F. Müller, C. W. de Pamphilis et al., "Mechanisms of functional and physical genome reduction in photosynthetic and nonphotosynthetic parasitic plants of the broomrape family," The Plant Cell, vol. 25, no. 10, pp. 3711-3725, 2013.

[21] M. Lavin, J. J. Doyle, and J. D. Palmer, "Evolutionary Significance of the Loss of the Chloroplast-DNA Inverted Repeat in the Leguminosae Subfamily Papilionoideae," Evolution, vol. 44, no. 2, p. 390, 1990.

[22] A. Zhu, W. Guo, S. Gupta, W. Fan, and J. P. Mower, "Evolutionary dynamics of the plastid inverted repeat: The effects of expansion, contraction, and loss on substitution rates," New Phytologist, vol. 209, no. 4, pp. 1747-1756, 2016.

[23] J. D. Palmer and W. F. Thompson, "Chloroplast DNA rearrangements are more frequent when a large inverted repeat sequence is lost," Cell, vol. 29, no. 2, pp. 537-550, 1982.

[24] V. Brázda, J. Kolomazník, J. Lýsek, L. Hároníková, and J. Coufal, "Palindrome analyser - A new web-based server for predicting and evaluating inverted repeats in nucleotide sequences," Biochemical and Biophysical Research Communications, vol. 478, no. 4, pp. 1739-1745, 2016.

[25] G. Navarro, "A guided tour to approximate string matching," ACM Computing Surveys, vol. 33, no. 1, pp. 31-88, 2001.

[26] S. Federhen, "The NCBI Taxonomy database," Nucleic Acids Research, vol. 40, no. 1, pp. D136-D143, 2012.

[27] I. Letunic and P. Bork, "Interactive tree of life (iTOL) v3: an online tool for the display and annotation of phylogenetic and other trees," Nucleic Acids Research, vol. 44, no. 1, pp. W242W245, 2016.

[28] H. Wickham, ggplot2: elegant graphics for data analysis, Springer, 2016.

[29] C. Sievert, C. Parmer, T. Hocking et al., plotly: Create Interactive Web Graphics via plotly.js, 2016.

[30] M. J. Moore, P. S. Soltis, C. D. Bell, J. G. Burleigh, and D. E. Soltis, "Phylogenetic analysis of 83 plastid genes further resolves the early diversification of eudicots," Proceedings of the National Acadamy of Sciences of the United States of America, vol. 107, no. 10, pp. 4623-4628, 2010.

[31] S. A. Muñoz-Gómez, F. G. Mejía-Franco, K. Durnin et al., “The New Red Algal Subphylum Proteorhodophytina Comprises the Largest and Most Divergent Plastid Genomes Known," Current Biology, vol. 27, no. 11, pp. 1677-1684.e4, 2017.

[32] E. D. Salomaki, K. R. Nickles, and C. E. Lane, "The ghost plastid of Choreocolax polysiphoniae," Journal of Phycology, vol. 51, no. 2, pp. 217-221, 2015.

[33] L. Lim and G. I. McFadden, "The evolution, metabolism and functions of the apicoplast," Philosophical Transactions of the Royal Society B: Biological Sciences, vol. 365, no. 1541, pp. 749763, 2010.

[34] J. Ma, B. Yang, W. Zhu, L. Sun, J. Tian, and X. Wang, "The complete chloroplast genome sequence of Mahonia bealei (Berberidaceae) reveals a significant expansion of the inverted repeat and phylogenetic relationship with other angiosperms," Gene, vol. 528, no. 2, pp. 120-131, 2013.

[35] M. Ueda, T. Nishikawa, M. Fujimoto et al., "Substitution of the gene for chloroplast RPS16 was assisted by generation of a dual targeting signal," Molecular Biology and Evolution, vol. 25, no. 8, pp. 1566-1575, 2008. 


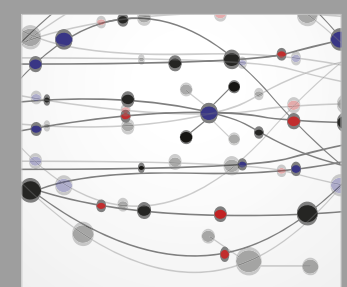

The Scientific World Journal
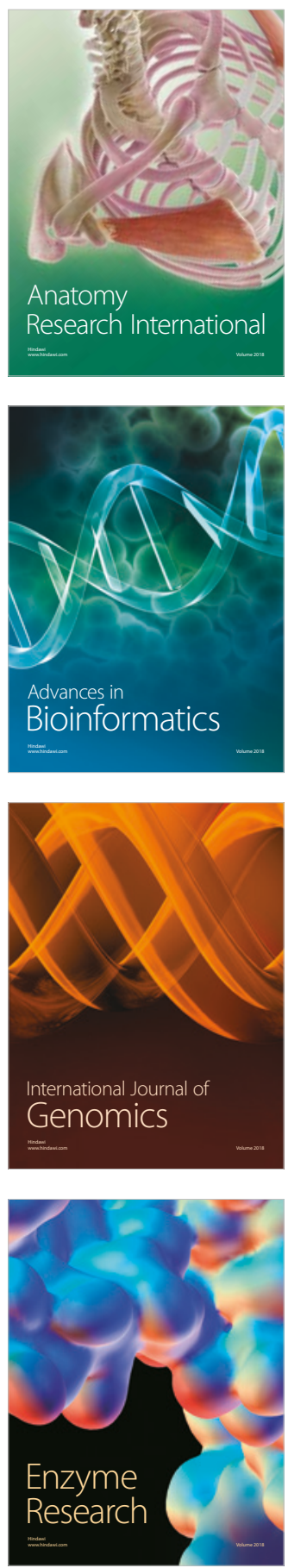
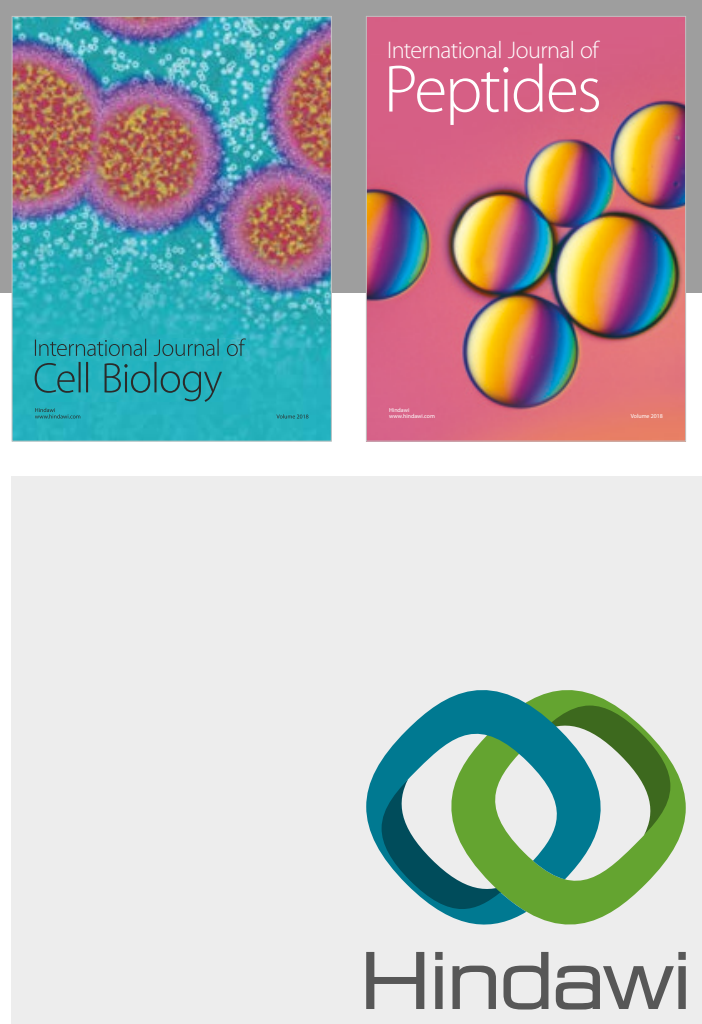

Submit your manuscripts at

www.hindawi.com
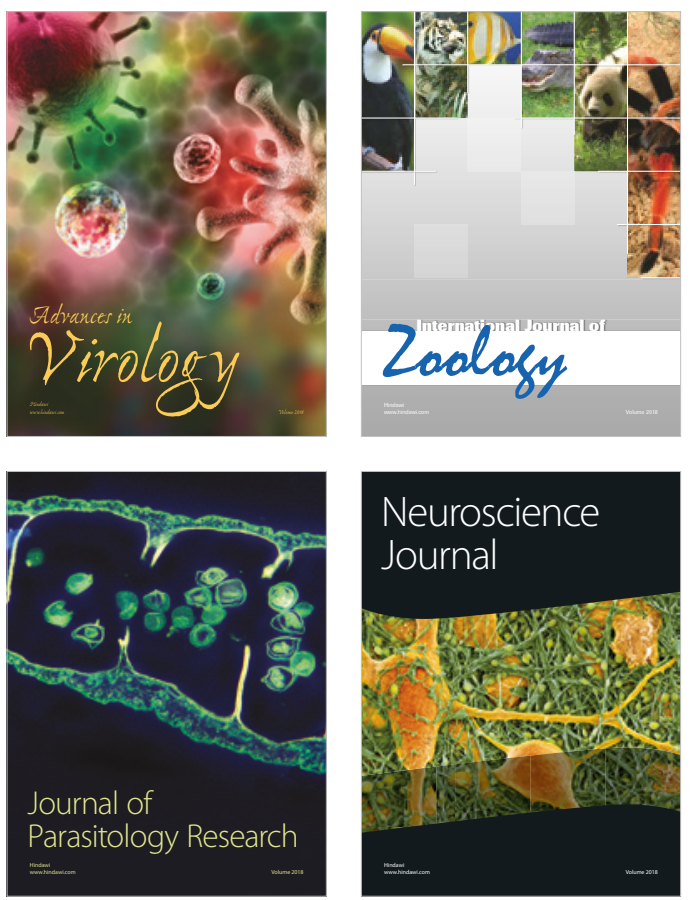
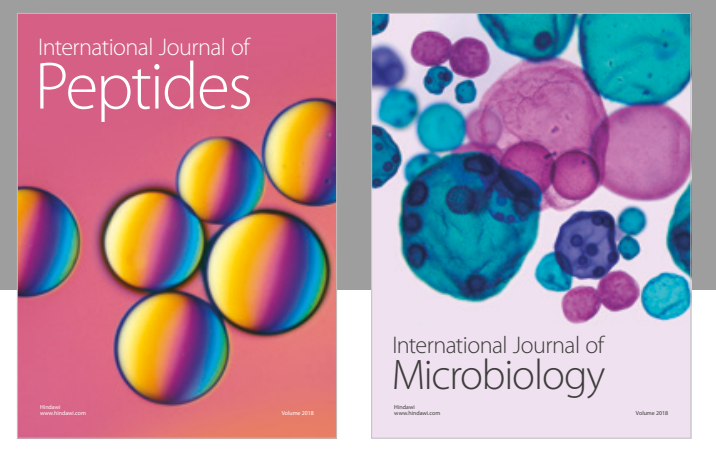

nternational Journal of Microbiology
Journal of
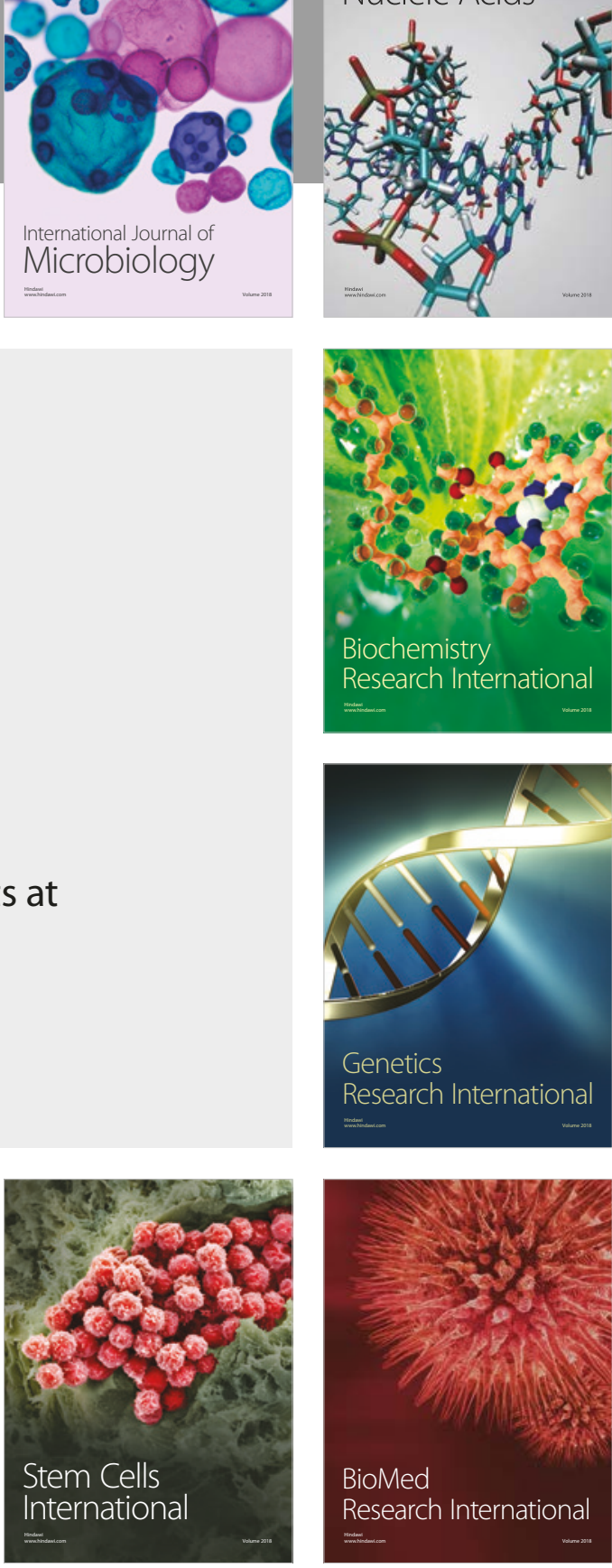
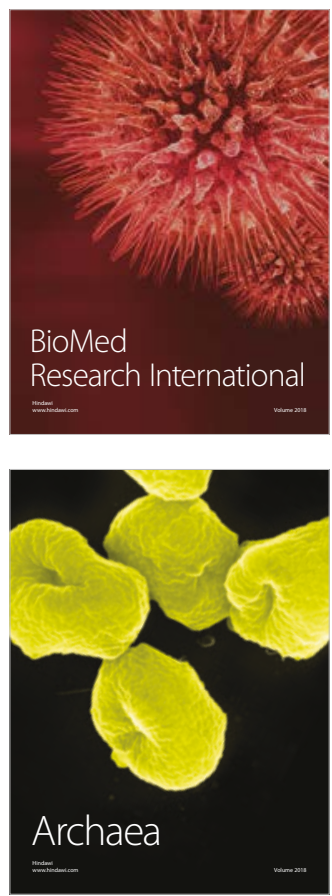